\title{
Non-pharmacological interventions for aggression in persons with dementia: A 10-year follow-up review of the literature
}

\author{
Caroline Kinskey, Jeffrey A. Buchanan* \\ Minnesota State University, Mankato, United States
}

Received: December 12, 2017

DOI: $10.5430 / \mathrm{cns} . v 6 n 3 p 8$
Accepted: January 16, 2018

Online Published: January 23, 2018

\begin{abstract}
Aggression is a common behavior in persons with dementia (PWDs). Nursing staff report that aggression is the most distressing behavior they face on the job. In addition, aggression may result in the prescription of psychotropic medications, which are largely ineffective and have dangerous side effects. Therefore, non-pharmacological interventions are necessary to safely manage aggressive behaviors and target the underlying cause of aggression. The current paper is a 10-year follow-up to Buchanan and colleagues' 2007 literature review of non-pharmacological interventions for aggression in PWDs. This paper has three primary purposes: (1) To update the review of the empirical literature in this area; (2) To examine how limitations in the literature have been addressed over the past 10 years; and (3) To suggest areas of future inquiry. Findings suggest that comprehensive staff training interventions and distraction-based interventions during activities of daily living (ADLs) show the most promise for managing aggression in PWDs.
\end{abstract}

Key Words: Dementia, Alzheimer's disease, Aggression, Non-pharmacological

\section{INTRODUCTION}

Aggression is a common behavioral problem in persons with dementia (PWDs). Aggression can include physical behaviors (e.g., hitting, kicking, biting) and/or verbal behaviors (e.g., cursing, threatening) directed toward another person. Additional terms such as "resistance to care", "combative behavior" and "agitation" are sometimes used synonymously with aggression, although they may have slightly different meanings. For example, a closely related construct is "resistance to care", which is defined as any patient behavior which prevents or interferes with the performance of activities of daily living (ADLs) such as bathing, eating, toileting, dressing, or grooming. ${ }^{[1]}$ Defining characteristics of resisting care include: angry objections, verbal and physical abuse, hitting, slapping, biting, screaming, fleeing, arguing and agitation. Similarly, "agitation" is defined as inappropriate verbal, vocal, or motor activity not judged by an outside observer to result directly from perceptible needs or confusion of the agitated individual. ${ }^{[2]}$ Therefore, agitation is a broader construct because it includes not only aggressive behaviors, but also encompasses a variety of other behaviors such as wandering or disruptive vocalizations.

This paper will address the specific constructs of verbal and physical aggression as well as closely related constructs such as "resistance to care" that involve acts directed towards another person that can result in physical or emotional harm. On the other hand, literature concerning the construct of agitation is not the focus of this paper because agitation in-

${ }^{*}$ Correspondence: Jeffrey A. Buchanan; Email: jeffrey.buchanan@mnsu.edu; Address: Minnesota State University, 103 Armstrong Hall, Mankato, United States. 
cludes a broader range of behaviors, only some of which are directed toward other people. This paper focuses on aggression and resistance to care because these behaviors are highly prevalent and are often of clinical concern due to the considerable harm they can cause.

\subsection{Prevalence of aggression in PWDs}

Due to varying definitions and methods of measuring aggression across the literature, estimates of the prevalence of aggression in PWDs vary widely. ${ }^{[3]}$ In community-dwelling individuals the prevalence of aggression is estimated to be between $6 \%-26 \%,{ }^{[4,5]}$ although estimates are typically around $50 \%$ in PWDs residing in long-term care facilities. ${ }^{[6,7]}$ One study completed over 10 years found that up to $96 \%$ of PWDs display aggressive behavior during the course of the illness. ${ }^{[8]}$ Although aggression can occur in the early stages of dementia, the prevalence of aggression increases with the severity of cognitive impairment and the resulting deficits in the ability to understand care providers. ${ }^{[9]}$ For example, some studies indicate that approximately $50 \%$ of individuals with advanced dementia engage in aggressive behaviors. ${ }^{[5,10,11]}$

\subsection{Negative consequences of aggression}

Aggressive behavior can result in numerous negative consequences for PWDs and their caregivers. Aggressive behavior in PWDs results in greater caregiver burden, which frequently leads caregivers to place the PWD in a long-term care facility. ${ }^{[12,13]}$ Nursing home staff report that aggression is the most distressing behavior in PWDs, and approximately $50 \%$ of nursing assistants report being injured because of aggressive behavior. ${ }^{[14,15]}$ Caregivers who experience aggression from a PWD report higher caregiver burden, experience worse physical functioning, and have higher pain scores. ${ }^{[13]}$ In turn, this can lead to staff burnout and high turnover rates, which will likely reduce the quality of care and increase the cost of care.

To combat the problem of aggression in PWDs, medications are frequently the treatment of choice. Between 25\%-40\% of PWDs living in long-term care facilities are prescribed antipsychotic medication, and 15\%-30\% are prescribed benzodiazepines. ${ }^{[16]}$ Although time-limited prescription of antipsychotics may be warranted in cases of severe aggression, research generally indicates that medications are largely ineffective for reducing behavioral problems in PWDs. ${ }^{[17]}$ Medications often result in adverse effects such as increased risk of mortality, excessive sedation, increased risk of falls, lethargy, and disorientation. ${ }^{[18-22]}$

\subsection{Rationale for non-pharmacological approaches}

The use of psychotropic medications to reduce aggression overlooks the possibility that aggression may be related to environmental factors and may serve a communicative function for the PWD. For example, aggressive behaviors occur most frequently during ADLs such as bathing, dressing, and toileting, which naturally involve physical touch from a caregiver. ${ }^{[23-25]}$ In these circumstances, the PWD may feel vulnerable and scared, while also being unable to express their distress verbally. Therefore, from this perspective aggression is conceptualized as self-protective behavior that functions to terminate and/or escape an unpleasant situation. ${ }^{[26]}$ Given the functional nature of aggression, managing aggression with psychotropic medications is questionable ethically because they serve to suppress behavior instead of addressing its ultimate cause or purpose, and they commonly suppress some remaining adaptive behaviors. Consequently, non-pharmacological interventions strategies are clearly necessary to address these environmental causes of aggression in PWDs.

Fortunately, there is a growing demand for nonpharmacological interventions for the treatment of behavioral disturbances, such as aggression, in PWDs. In 2012, the Center for Medicare and Medicaid Services (CMS) publicized an initiative to improve dementia care and the quality of lives of those with dementia. A primary goal of the initiative is to identify and implement alternative interventions to antipsychotics, and reduce the overall use of antipsychotics in PWDs. ${ }^{[27]}$ Since 2012, there has been a significant reduction in the use of antipsychotics, but CMS's partnerships with nursing homes, caregivers, and other providers continues in an effort to reduce the rate even further. ${ }^{[28]}$ Identifying an array of effective non-pharmacological interventions is necessary to achieve this goal.

A previous review of non-pharmacological interventions for aggressive behavior in PWDs suggested that relatively few empirical studies focused exclusively on interventions for managing aggression in PWDs. ${ }^{[29]}$ Given that aggression is highly prevalent, results in many negative consequences, and the continued push to reduce antipsychotic use, an updated review of the literature on non-pharmacological interventions appeared warranted. Therefore, the current paper represents a 10-year follow-up to Buchanan and colleagues' 2007 literature review and has three primary purposes: (1) To update the review of the empirical literature in this area; (2) To examine how limitations in the literature have been addressed over the past 10 years; and (3) To suggest areas of future inquiry.

\section{METHOD AND PROCEDURES}

Articles reviewed for this paper met the following inclusion criteria: (1) All participants were diagnosed with a condition that causes progressive dementia; (2) The study was empirical in nature as opposed to being a narrative case description, 
or simply a description of an intervention that included no data collection; (3) The study utilized an intervention that did not involve the use of medication; (4) The study included a specific quantitative measure of aggression (e.g., direct observation, validated questionnaires); and (5) The study was published between 2007 and 2017.

As mentioned previously, "agitation" is a frequently used term in the literature and refers to a wide assortment of physically nonaggressive (e.g., pacing, hiding things), physically aggressive (e.g., hitting, kicking), verbally nonaggressive (e.g., complaining, negativism), and verbally aggressive behaviors (e.g., screaming, cursing). ${ }^{[30]}$ Therefore, "agitation" is a much broader construct that includes a number of behaviors that are nonaggressive and do not cause direct harm to others (e.g., repeating statements or mannerisms, restlessness). This review focuses on interventions specifically for aggressive behaviors because aggression is highly prevalent, is of greatest clinical concern for care providers, can result in injuries to care providers and PWDs, and is a primary reason why potentially harmful psychotropic medications are prescribed to PWDs. When conducting the literature search, many studies included samples of individuals exhibiting "agitated" behaviors, which may or may not have involved engaging in aggressive behaviors. When the description of a study made it difficult to determine the impact of an intervention on those participants specifically displaying aggressive behavior, ${ }^{[9]}$ the study was excluded from this review.

To conduct the initial search for articles meeting the inclusion criteria, combinations of the following search terms were used: "dementia", "Alzheimer's", "aggression", "behavioral", "intervention", "resistance to care", "rejection of care", "non-pharmacological", "protective behaviors", "combative" and "violent". The PsychInfo and Ageline electronic databases were used to conduct this initial search. After obtaining this initial set of articles based on online database searches, the first author reviewed the citations within each of those articles to identify additional relevant studies. Next, a careful review of the "method" section of each article was completed to ensure each study met the inclusion criteria. In cases where there were questions about the appropriateness of a study, the two authors reviewed the article and made a final decision. Upon completion of this process, 12 articles were included in this review (see Table 1).

\section{REVIEW OF THE LITERATURE}

\subsection{Introducing novel stimuli into the environment}

Three studies implemented interventions that involved introducing novel and potentially enjoyable activities into the general milieu of a long-term care setting. These interventions are based on the premise that these activities will have a general calming influence on PWDs, resulting in a more specific effect such as reducing aggression. This category of interventions is similar to the category of "activity-based interventions" described by Buchanan and colleagues, ${ }^{[29]}$ which included a variety of interventions that involved incorporating activities (e.g., spa baths, swinging on gliders, walking, music therapy) into the day-to-day life of PWDs with the goal of impacting aggression.

One example of this type of intervention approach is a study by Nordgren and Engström ${ }^{[31]}$ that evaluated the effect of a dog-assisted intervention on symptoms of dementia. Thirtythree individuals with dementia from eight nursing homes in Sweden participated in the study. Participants were assigned to an intervention group $(n=20)$ or a no treatment control group $(n=13)$. The intervention consisted of ten sessions lasting between 45 and 60 minutes over a six-month period. Intervention protocols varied depending on the residents' needs, but could include various activities, such as walking the dog, playing with the dog, petting the dog, feeding it, talking to it, brushing it, reminiscing about pets, and talking to the dog handler. The researchers used the Cohen-Mansfield Agitation Inventory (CMAI) ${ }^{[32]}$ to measure several behaviors, including physically aggressive behaviors. Nurses completed the CMAI at baseline, post-intervention, a 3-month followup, and a 6-month follow-up. There was not a significant change in the level of physically aggressive behaviors in the intervention group compared to the control group.

Chang et al. ${ }^{[33]}$ evaluated an 8-week music program for 41 residents with dementia displaying problematic behaviors. The intervention included playing various types of music (e.g., nature sounds, piano music) during lunchtime. A quasiexperimental design was used that involved alternating music and no-music conditions on a weekly basis, which resulted in four weeks with music and four weeks without music. Nurses and social workers blind to the purpose of the study observed residents and completed the CMAI to evaluate problem behaviors throughout the day, including physically aggressive behavior and verbally aggressive behavior. Unexpectedly, results showed that aggressive behavior was more prevalent during weeks when music was played compared to weeks when it was not played during the lunchtime period. Interestingly, the authors concluded that the music intervention was effective, but had a delayed effect where the impact of the intervention was not realized until a week later, making it appear as if aggression was lower in the no music condition. Unfortunately, this conclusion is not supported by the data nor was a testable theory articulated to support this interpretation of the data. 
Table 1. Summary of reviewed articles

\begin{tabular}{|c|c|c|c|c|}
\hline Article & $\begin{array}{l}\text { Number of } \\
\text { Participants }\end{array}$ & Measures of aggression & Intervention & Results \\
\hline $\begin{array}{l}\text { Chang et al., } \\
2010\end{array}$ & $N=41$ & $\begin{array}{l}\text { Chinese version of the } \\
\text { Cohen-Mansfield Agitation } \\
\text { Inventory (CMAI) }\end{array}$ & $\begin{array}{l}\text { An eight-week time series design was used. Music and no music conditions } \\
\text { during lunchtime were alternated each week after baseline. Music included a } \\
\text { single piano, and "nature music" such as bird sounds, whale songs, and } \\
\text { running water. }\end{array}$ & $\begin{array}{l}\text { Problem behavior scores rose during } \\
\text { weeks when the music program was } \\
\text { applied. }\end{array}$ \\
\hline $\begin{array}{l}\text { Chou et al., } \\
2016\end{array}$ & $N=4$ & $\begin{array}{l}\text { Agitated Behavior Scale } \\
\text { (ABS) }\end{array}$ & $\begin{array}{l}\text { Preliminary study: Researchers presented residents with } 15 \text { pictures. The } \\
\text { picture that the resident showed the most positive response to was used in the } \\
\text { individual's intervention trial. } \\
\text { Experimental analysis: If combative behaviors occurred during ADLs, an } \\
\text { intervention or control trial occurred. } \\
\text { Intervention trial: CNA showed pictures from the preliminary study to the } \\
\text { resident and then continued providing care. The resident could hold the } \\
\text { picture if desired. } \\
\text { Control trial: Same as intervention trial, except stimulus card was blank. }\end{array}$ & $\begin{array}{l}\text { Each resident showed a decrease in } \\
\text { ABS scores after the intervention. }\end{array}$ \\
\hline $\begin{array}{l}\text { Chrzescijanski } \\
\text { et al., } 2007\end{array}$ & $\begin{array}{l}N=128 \\
\text { Residents: } n=43 \\
\text { Staff: } n=85\end{array}$ & BAGS Aggression Scale & $\begin{array}{l}\text { A staff education intervention called Emotional Responses as Quality } \\
\text { Indicators (ERIC) with the aim of improving staff understanding of the } \\
\text { emotions and subsequent needs of the person with dementia. Involved staff } \\
\text { watching a } 40 \text {-minute video, which showed } 6 \text { emotions commonly displayed } \\
\text { by people with dementia. }\end{array}$ & $\begin{array}{l}\text { Aggression scores following the } \\
\text { intervention resulted in a lower } \\
\text { frequency of episodes, but similar } \\
\text { intensity in aggression scores. }\end{array}$ \\
\hline $\begin{array}{l}\text { Deudon et al., } \\
2009\end{array}$ & $\begin{array}{l}306 \text { participants } \\
\text { Intervention group: } \\
n=158 \\
\text { Control group: } n=114\end{array}$ & CMAI & $\begin{array}{l}\text { Staff training program: began with a 90-minute teaching session on } \\
\text { dementia, behavioral problems, and the use of "how to" instruction cards. } \\
\text { The training program also had individual and interactive sessions in which } \\
\text { the trainers provided feedback on how staff members were dealing with the } \\
\text { problems. } \\
\text { Total training time was } 24 \text { hours. }\end{array}$ & $\begin{array}{l}\text { Between baseline and week } 8 \text {, the } \\
\text { intervention group had a significant } \\
\text { decrease in global CMAI scores, } \\
\text { physically nonaggressive scores, } \\
\text { verbally nonaggressive scores, and } \\
\text { verbally aggressive scores. These } \\
\text { differences were not seen in the } \\
\text { control group. } \\
\text { Between baseline and week 20, there } \\
\text { was a significant decrease in global } \\
\text { CMAI scores, physically } \\
\text { nonaggressive scores, and verbally } \\
\text { nonaggressive scores in the } \\
\text { intervention group, but not the } \\
\text { control group. }\end{array}$ \\
\hline $\begin{array}{l}\text { Fisher \& } \\
\text { Buchanan, in } \\
\text { press }\end{array}$ & $N=1$ & $\begin{array}{l}\text { Frequency count of verbal } \\
\text { and physical aggression }\end{array}$ & $\begin{array}{l}\text { Nursing staff provided access to a preferred stimulus for one minute prior to } \\
\text { caregiving and to continually direct the attention of the resident to the } \\
\text { stimulus during the care task. }\end{array}$ & $\begin{array}{l}\text { Both physical and verbal aggression } \\
\text { reliably declined during the } \\
\text { intervention phases. }\end{array}$ \\
\hline Fu et al., 2013 & $\begin{array}{l}N=67 \\
\text { Aromatherapy: } n=23 \\
\text { Combination: } n=22 \\
\text { Control: } n=22\end{array}$ & CMAI & $\begin{array}{l}\text { Participants were randomly assigned to receive six weeks of twice daily } \\
\text { aromatherapy only, aromatherapy with hand massage, or a water spray } \\
\text { (placebo). }\end{array}$ & $\begin{array}{l}\text { Aromatherapy alone and } \\
\text { aromatherapy with hand massage } \\
\text { did not reduce aggression. }\end{array}$ \\
\hline $\begin{array}{l}\text { Gozalo et al., } \\
2014\end{array}$ & $N=240$ & $\begin{array}{l}\text { Care Recipient Behavior } \\
\text { Assessment }\end{array}$ & $\begin{array}{l}\text { The intervention involved different techniques designed to make showering, } \\
\text { tub bathing, in-room bathing, and hair washing safe and comfortable for the } \\
\text { persons receiving and giving care. }\end{array}$ & $\begin{array}{l}\text { There was a reduction in aggressive } \\
\text { and agitated behaviors. } \\
\text { Verbal behaviors declined } \\
\text { significantly. } \\
\text { Combined verbal and physical } \\
\text { behaviors declined significantly. } \\
\text { Antipsychotic use declined } \\
\text { significantly after the intervention. }\end{array}$ \\
\hline $\begin{array}{l}\text { Hammar et al., } \\
2010\end{array}$ & $N=10$ & Resistiveness to Care Scale & $\begin{array}{l}\text { PWDs were video-observed four times during "ordinary" morning care tasks } \\
\text { and four times with caregivers singing during morning care tasks. }\end{array}$ & $\begin{array}{l}\text { Resistance to care behavior } \\
\text { significantly decreased when the } \\
\text { intervention was in place. } \\
\text { Other behaviors, like hitting and } \\
\text { kicking decreased, but not } \\
\text { significantly. }\end{array}$ \\
\hline $\begin{array}{l}\text { Karlin et al., } \\
2014\end{array}$ & $\begin{array}{l}N=71(64 \text { completed } \\
\text { the program) }\end{array}$ & $\begin{array}{l}\text { STAR-VA ABC Card } \\
\text { behavioral severity and } \\
\text { frequency scales } \\
\text { Revised Memory and } \\
\text { Behavior Problems } \\
\text { Checklist }\end{array}$ & $\begin{array}{l}\text { The intervention consisted of three primary components: } \\
\text {-Identifying and changing activators to, and consequences of, challenging } \\
\text { behaviors. } \\
\text {-Increasing pleasant events that fit with the resident's current life } \\
\text { circumstances. } \\
\text {-Educating staff about dementia. }\end{array}$ & $\begin{array}{l}\text { The intervention led to significant } \\
\text { reductions in the frequency and } \\
\text { severity of challenging dementia } \\
\text { related behaviors, including } \\
\text { violence/aggression. }\end{array}$ \\
\hline $\begin{array}{l}\text { Nordgren and } \\
\text { Engström, } 2014\end{array}$ & $\begin{array}{l}N=23 \\
\text { Intervention group: } \\
n=20 \\
\text { Control group: } n=13\end{array}$ & CMAI & $\begin{array}{l}\text { Ten sessions lasting between } 45 \text { and } 60 \text { minutes over a six-month period. } \\
\text { Intervention protocols varied, but could include activities, such as walking } \\
\text { the dog, playing with the dog, petting the dog, feeding it, talking to it, } \\
\text { brushing it, reminiscing about pets, and talking to the dog handler. }\end{array}$ & $\begin{array}{l}\text { There was not a significant change in } \\
\text { the level of physically aggressive } \\
\text { behaviors in the intervention group } \\
\text { compared to the control group. }\end{array}$ \\
\hline Shin, 2015 & $N=51$ & $\begin{array}{l}\text { Quality of life in late-stage } \\
\text { dementia scale }\end{array}$ & $\begin{array}{l}\text { Access to baby-like dolls. Residents chose a doll to take, and were asked to } \\
\text { hold them. Residents that were uncomfortable or refused were not given } \\
\text { dolls. }\end{array}$ & $\begin{array}{l}\text { At a statistically significant level, } \\
\text { older adults used less swear } \\
\text { words/shouted less, were less } \\
\text { aggressive, and wandered less } \\
\text { following the intervention. }\end{array}$ \\
\hline $\begin{array}{l}\text { Visser et al., } \\
2008\end{array}$ & $\begin{array}{l}\text { Residents: } n=76 \\
\text { Staff: } \\
\text { Education only group: } \\
n=21 \\
\text { Education }+ \text { Peer } \\
\text { support group: } n=32\end{array}$ & CMAI & $\begin{array}{l}\text { Facilities were randomly assigned to one of two eight-week behaviorally } \\
\text { based educational intervention groups. One facility also participated in a } \\
\text { peer support group to reinforce educational material and create a supportive } \\
\text { environment for staff. }\end{array}$ & $\begin{array}{l}\text { No significant reduction in } \\
\text { aggression. } \\
\text { Peer support was not more effective. }\end{array}$ \\
\hline
\end{tabular}


$\operatorname{Shin}^{[34]}$ conducted a doll therapy intervention using a pretestposttest design with 62 residents with dementia in a Korean nursing home. The residents voluntarily took a baby doll (which was 3 pounds, 17 inches long, and had realistic black hair), and always had access to the doll. The researchers instructed staff to refer to the dolls as "dolls" if residents believed they were dolls, and refer to the dolls as "babies" if the resident believed they were babies. Subcategories of the Quality of Life in Late-Stage Dementia (QUALID) ${ }^{[35]}$ were used to measure changes in behavior, including physical aggression. The QUALID was completed by staff at baseline, one-month, and 3 months after the dolls had been distributed to the residents. In the 51 participants that completed the intervention, significant reductions in aggression were found at both the one-month and three-month follow-up.

Fu et al. ${ }^{[36]}$ investigated the effectiveness of aromatherapy and aromatherapy combined with hand massage in reducing aggression. The 67 participants in the study were randomly assigned to receive twice-daily aromatherapy, aromatherapy with hand massage, or water spray (placebo) for six weeks. The aromatherapy spray contained 3\% lavender oil, which is thought to promote relaxation. The CMAI was used to measure verbal and physical aggression. The CMAI was completed five times by a small group of staff that regularly cared for the individual being evaluated. There were no significant reductions in verbal or physical aggression during or following the intervention.

\subsection{Staff interventions}

Five studies since 2007 investigated the effects of staff intervention programs designed to reduce aggressive behavior in PWDs. Chrzescijanski et al. ${ }^{[37]}$ implemented a staff education program to change staff attitudes and perceptions regarding PWDs, with the goal of reducing aggression in residents. Staff participated in the Emotional Responses as Quality Indicators in Care (ERIC) program that is designed to improve staff understanding of the emotions, behaviors, and needs of a PWD. The effectiveness of the intervention was evaluated using an interrupted time series design where the resident served as his/her own comparison. Four residential care settings in Australia took part in the staff intervention and 43 residents were included in the study. The BAGS Aggression Scale, which measures aggression hourly, was completed by caregivers to evaluate changes in aggression during the 14-day observation period. ${ }^{[38]}$ The frequency of aggression declined following the ERIC intervention, but intensity of aggression did not change. Also, the difference in the total mean aggression scores was not statistically significant.

Deudon and colleagues ${ }^{[39]}$ conducted a randomized con12 trolled trial in 16 nursing homes with 306 individuals with dementia. An eight-week staff education and training program was completed in the nursing homes with the goal of reducing problem behaviors, including aggression. In total, the staff education program was 24 hours and involved teaching staff guidelines about how to best manage specific problem behaviors. Training involved interactive sessions where feedback was provided to staff when working with residents. The CMAI was used to measure physical and verbal aggression, and data was collected at baseline, eight weeks, and a 20-week follow-up. A significant reduction on the verbal aggression subscale of the CMAI was found for the intervention group compared to the control group at week 8 , but not at the 20 -week follow-up. There was no significant difference between groups on the physical aggression subscale of the CMAI.

Gozalo et al. ${ }^{[40]}$ investigated the effectiveness of the Bathing Without a Battle (BWAB) educational program in reducing physically and verbally aggressive behaviors in residents with dementia. The intervention teaches staff techniques for bathing residents with dementia in a manner that is safer and more comfortable for both the resident and staff member. The Care Recipient Behavior Assessment (CAREBA) was used to measure the primary outcome variables, which were the rate of physically aggressive behaviors and verbally aggressive or agitated behaviors during bathing. Three baths were observed for each participant. Half of the facilities $(n=3)$ in the study completed observations at baseline and twice post-intervention. The other half of the facilities served as a control and had two pre-intervention observations, followed by one post-intervention observation. Each round of observations lasted two to four months depending on the size of the facility. A total of 240 nursing home residents with dementia took part in the intervention. Following the intervention, there was an overall significant reduction in verbally aggressive/agitated behavior, aggressive language, and the combined presence of physically or verbally aggressive or agitated behavior. However, there was not a significant reduction in physically aggressive behavior.

Karlin et al. ${ }^{[41]}$ evaluated a behavioral intervention developed by the U.S. Department of Veteran Affairs health care system for veterans with dementia titled STAR-VA. The intervention had the following three primary components: (1) Identifying and changing activators to, and consequences of, challenging behaviors; (2) Increasing personally relevant and pleasant events for the resident through a structured and individualized process; and (3) Promoting communication and educating staff on realistic expectations of individuals with dementia. Sixty-four veterans completed the intervention, but aggression was specifically targeted in only 
11 of these participants. Although the length of the intervention varied depending on the challenging behavior (range $=$ 4-147 days), the intervention lasted an average of 46 days. Compared to baseline measurements, there was a significant decrease in the frequency of violent/aggressive behavior in the targeted participants.

Visser et al. ${ }^{[42]}$ investigated the effectiveness of a staff education program in increasing quality of life in residents with dementia, targeting multiple behavioral symptoms, including aggression. Staff learned to identify possible antecedents and consequences of behaviors as well as strategies for modifying behaviors. The education program lasted approximately eight weeks, with two 1-1.5 hour sessions each week. Three facilities took part in the study, with one facility receiving education-only, another receiving education plus peer support, and the control facility receiving no intervention. In total, 52 staff and 76 residents participated. The CMAI was used to measure physically aggressive and verbally aggressive behavior. Following the intervention, there were no significant differences found between groups in terms of frequency of physical and verbal aggression.

\subsection{Use of distractors during ADLs}

Three studies utilized preferred objects/stimuli as distractors in an effort to reduce aggression in PWDs during ADLs. Chou et al. ${ }^{[43]}$ used 15 images from the International Affective Pictures System (IAPS) ${ }^{[44]}$ that elicit positive emotion according to normative data. Four female residents who engaged in combative behaviors during dressing/toileting activities were included in the study. Before starting the initial experiment, a preliminary study was conducted with each resident to determine what image resulted in the most positive response. Three of the four residents preferred the image of a baby, and the fourth resident had the most positive response to an image of puppies. The researchers used the Agitated Behavior Scale (ABS) ${ }^{[45]}$ to measure resistance to care and combative behaviors during ADLs. During the experimental trials, the preferred stimulus was only presented if the resident resisted care and became combative. All four residents had a decrease in ABS scores after the intervention.

Hammar et al. ${ }^{[4]}$ implemented an intervention with ten PWDs in which caregivers sang to residents during morning care routines. Prior to implementing the intervention, the 10 participants were observed via video four times during the morning care routine over a period of two months. For the intervention, caregivers sang songs that would be recognizable to the resident during the morning care routine, sometimes stopping to provide instruction. The Resistiveness to Care Scale (RTCS) ${ }^{[47]}$ was used to measure the duration and intensity of aggressive behaviors such as: pushing away,

Published by Sciedu Press pushing/pulling, hitting or kicking, and threatening. Each participant was videotaped four times during the intervention period. Aggressive behaviors decreased during the music intervention compared to baseline, but findings were not statistically significant.

Fisher and Buchanan ${ }^{[48]}$ examined the use of exposure to preferred stimuli during ADLs as a means for reducing aggressive behavior in an 88-year-old female diagnosed with Alzheimer's disease. The intervention was evaluated using an A-B-A-B single-subject research design. The rate of verbally and physically aggressive behaviors were directly observed while staff assisted the resident preparing for bed, which was the most challenging ADL to complete. Preferred stimuli were assessed using a paired stimulus preference assessment where the resident was repeatedly presented pairs of eight objects and preference for each object (e.g., touching objects, smiling) was observed. A video of babies was the most preferred stimulus. Nursing staff were instructed to provide access to the stimulus for one minute prior to caregiving and to continually direct the attention of the resident to the stimulus during the care task. Both physical and verbal aggression reliably declined during the intervention phases.

\section{Summary OF THE Literature}

It is surprising that over the past 10 years that only 12 additional studies were devoted to evaluating nonpharmacological interventions for managing aggressive behaviors in PWDs. More commonly found in the literature are interventions that target "agitation", which includes behaviors such as wandering, restlessness, making strange noises as well as aggression. However, aggression requires study as a separate entity because of its unique nature, namely that it is highly stressful and possibly dangerous. In essence, although care providers can conceivably ignore or avoid many other "agitated" behaviors, aggression often is unavoidable because it most often occurs during ADLs that must be completed and involve close personal contact with PWDs. Therefore, it is important for direct care workers to have a variety of specific skills to manage these challenging and potentially dangerous situations.

Comprehensive staff education and training programs that target the management or prevention of aggression have generally produced the most positive results. Prior to 2007, four studies found that training programs for nursing staff were effective. ${ }^{[14,49-51]}$ More recently, three staff intervention studies found significant reductions in aggression. ${ }^{[39-41]}$ These programs tend to involve multiple sessions and teach specific skills such as identifying and modifying environmental precipitants of aggression, communication techniques, learning to view problem behaviors as an expression of an unmet need, 
learning to examine antecedents to aggressive behaviors and their consequences, and distraction. One important feature of some training programs evaluated is that there was an emphasis placed on individualizing intervention strategies based on a "menu" of more general strategies. This approach seems warranted given the multitude of potential variables related to aggression and the variety of intervention approaches that are available. On one hand, each individual and situation is unique and requires an individualized approach; on the other hand, one needs a set of evidence-based strategies from which to choose when devising an individualized treatment plan. Therefore, teaching a broad set of behavior management skills as well as problem solving strategies for choosing which skills to use in novel situations appears to provide an efficient way to address aggression and potentially minimizes the need for extensive, ongoing training.

Three studies investigating distraction-based interventions support conclusions drawn from previous reviews ${ }^{[29]}$ suggesting that this intervention approach may be particularly promising for reducing aggression during ADLs. The strength of this approach is that the rationale behind it is straightforward and it requires less training time compared to the comprehensive training approaches described earlier. In other words, one can potentially get a lot of "bang for their buck" with this approach because the intervention is easy to implement, requires relatively little training, and may produce reductions in aggressive acts in situations where they are most likely to occur. One key aspect of successful distraction-based interventions appears to be identifying distractors that are engaging to the PWD. Although individualized distractors can be identified in several ways (e.g., casual observation of the resident, asking caregivers), the studies by Fisher and Buchanan ${ }^{[48]}$ and Chou et al., ${ }^{[43]}$ suggest that formal preference assessment procedures can also be useful. These procedures involve observing PWDs interacting with objects/activities and measuring indicators of preference such as positive emotional reactions or making physical contact with an object/activity. These preference assessment procedures require an additional investment of time prior to starting an intervention, but may be worth this investment in terms of improving outcomes.

Recent studies have examined the incorporation of stimuli or activities such as animals, music, aromatherapy, or lifelike dolls into the general milieu of long-term care settings. The four studies reviewed that implement this approach produced mixed results, with three finding no effect ${ }^{[31,33,36]}$ and one finding a significant effect. ${ }^{[34]}$ Similar conclusions were made by Buchanan and colleagues ${ }^{[29]}$ regarding "activitybased interventions" such as walking groups, music therapy, social gatherings, night-time spa baths, or swinging. Overall, the approach of simply increasing various kinds of activity or introducing novel stimuli into the living environment has had limited impact on aggression.

\subsection{Revisiting limitations in the literature and sugges- tions for future research}

Given the small body of research on non-pharmacological interventions targeting aggression in PWDs, it is important that research in this area continue in order to identify evidencebased practices that can be disseminated and implemented with minimal training. The following sections will revisit limitations in the literature identified by Buchanan et al. ${ }^{[29]}$ to determine the extent to which these limitations have been addressed in the past decade.

\subsection{Targets of interventions}

Aggression in PWDs is typically not random. Instead, aggressive behavior most often occurs during ADLs that require caregivers to have physical contact with PWDs. ${ }^{[23-25]}$ Also, as mentioned previously, long-term care staff report aggression during ADLs as highly distressing, and there is an increased risk of injury to both caregivers and PWDs. ${ }^{[14,15]}$ In our previous review, only 6 of 18 studies specifically targeted aggression during ADLs and it was recommended that additional studies address this important issue. ${ }^{[29]}$ Since that time, just four additional studies that met the inclusion criteria have been devoted specifically to addressing aggression during ADLs. ${ }^{[40,43,46,48]}$ Overall, there appears to be continued need for empirical research addressing aggressive behavior that occurs during intimate caregiving situations.

\subsection{Research design limitations}

The studies reviewed here used a variety of different experimental designs. Most notably, only four were randomized control trials that utilized "gold standard" experimental methods such as random assignment and inclusion of a control group. ${ }^{[31,36,39,40]}$ Two of these studies utilized designs where facilities were randomly assigned to experimental conditions and included adequate sample sizes of over $200,{ }^{[39,40]}$ whereas two studies ${ }^{[31,36]}$ included random assignment of participants to conditions, but with smaller sample sizes ( $N=67$ and $N=33$, respectively).

In addition, six studies used pre-post designs that did not include control groups. These studies provide valuable information about the potential effectiveness of an intervention, but the conclusions that can be drawn are limited because natural reductions in aggression that can occur over time without intervention are not measured. ${ }^{[34,37,41-43,46]}$ Furthermore, four of these studies included small samples (i.e., $\mathrm{N}<12$ ) of aggressive residents. 
Finally, one study utilized single-case experimental design with one participant. ${ }^{[48]}$ Although the findings of this study were promising, the generalizability of findings is limited and the experimental phases were relatively short, making it difficult to determine if the intervention had a reliable, long-term effect on aggression. Overall, it appears as if the literature in this area is still beset by small sample sizes and other methodological problems that must be addressed in future research to ensure the generalizability of results across PWDs.

\subsection{Limitations in measurement}

Buchanan et al. ${ }^{[29]}$ noted there was an over-reliance on the use of self-report measures of aggression (e.g., the CohenMansfield Agitation Inventory) and they recommended that future studies incorporate a multi-method approach to assess aggression. Although self-report measures are a necessary component of the assessment process, these instruments are prone to recall biases. Unfortunately, of the 12 studies reviewed in this paper, eight relied solely on self-report instruments from the staff to measure aggression, while four studies used a combination of self-report measures and other methods such as direct observation that are less likely to be affected by caregiver biases. The use of multiple methods and informants (e.g., care providers, outside observers) continues to be advised as a means for ensuring that conclusions regarding the effectiveness of interventions are valid.

\subsection{Lack of social validity measures}

It is important to measure how meaningful treatments effects are to the participants in a study. Statistically significant results do not always manifest themselves as clinically meaningful results in the natural environment. Therefore, it is necessary to measure social validity, which Wolf ${ }^{[52]}$ described as the assessment of: (1) The social significance of treatment goals; (2) Social appropriateness or acceptability of interventions; and (3) The social importance of the effects of interventions. Only $17 \%$ (2 of 12) of the studies in this review formally evaluated staff perception of the acceptability or effectiveness of the intervention, which is very similar to the findings of Buchanan and colleagues ${ }^{[29]}$ where $22 \%$ (4 of 18) included such a measure.

Exceptions to this trend included Chou et al. ${ }^{[43]}$ and Visser et al. ${ }^{[42]}$ Chou and colleagues used the Distress Thermometer to measure a CNA's level of distress in relation to providing care to residents. ${ }^{[53]}$ Levels of caregiver distress decreased significantly following the intervention, suggesting that care providers found their jobs less difficult following the intervention. Taking a different approach to measuring social validity, Visser and colleagues ${ }^{[42]}$ measured job-related feel- ings using the Maslach Burnout Inventory, ${ }^{[54]}$ but found no significant changes in scores following the intervention.

Findings regarding social validity are noteworthy because they: (1) Evaluate whether care providers found an intervention worth the time to learn and implement; (2) Reveal whether interventions impact caregiver well-being; (3) Indicate whether caregivers detect the impact of interventions in their day-to-day lives and, therefore; (4) Suggest whether caregivers will continue to use an intervention after a study is completed. Overall, future studies should assess the impact of interventions on caregivers, because they also stand to benefit from many of these interventions and they are ultimately responsible for implementing them.

\subsection{Lack of follow-up}

Follow-up assessment is necessary to evaluate whether the effects of an intervention maintain over time. This is an important consideration because cognitive and physical impairments associated with dementia become more severe over time, which could alter the effectiveness of an intervention. Only five of the studies (42\%) reviewed, however, conducted follow-up assessments that ranged from six weeks to six months. ${ }^{[31,33,36,39,42]}$ These findings represent a slight improvement from those of Buchanan et al., ${ }^{[29]}$ who found that only $22 \%$ studies included any kind of follow-up assessment. Nevertheless, more studies must assess whether treatment gains maintain over time as the disease progresses and what sorts of modifications are necessary to accommodate this progression. Likewise, data concerning the use of interventions following the completion of research studies are needed to determine if effective interventions continue to be implemented once researchers are gone. Data of this kind could be invaluable for identifying characteristics of treatment approaches (e.g., time needed to learn and implement; simplicity), that are not only effective, but also acceptable to care providers.

\subsection{Lack of individualization}

Although some interventions may be effective for a broad range of PWDs, adequately addressing aggression for a given individual may require an individualized approach to assessment and intervention. For example, aggression may occur for different reasons, so an individualized assessment strategy may be necessary to understand the causes of aggression for a particular individual. Likewise, some intervention strategies involve the introduction of objects or activities into caregiving environments. The effectiveness of these interventions may be reliant upon whether these objects or activities are interesting or preferred by participants. Although these observations may seem incontrovertable, Buchanan et al. ${ }^{[29]}$ 
reported that many studies failed to individualize assessment and treatment approaches. Since that time, more studies have attempted to individualize assessment strategies and interventions to the unique needs of PWDs. For example, most staff training studies (i.e., 80\%) taught caregivers strategies for assessing unique causes of aggression for PWDs and developing intervention strategies based on that assessment. In addition, two of the distraction-based studies attempted to identify individual preferences so the distractors used would be personally relevant.

This lack of individualization is most notable in relation to interventions that involved "introducing novel stimuli into the environment" or similar studies that Buchanan et al. ${ }^{[29]}$ labeled "activity-based interventions". This intervention approach also produced some of the most inconsistent and disappointing results. One reason for these negative findings may be that making broad environmental changes such as introducing animals or dolls into a long-term care facility, having nighttime spa baths, or playing music during meals does not adequately address the unique environmental causes/functions of aggression for different PWDs. For example, it is unclear if the mechanism of action of these interventions is to create a calming environment in order to minimize the impact of environmental overstimulation as an antecedent to aggression or if they are designed to increase environmental stimulation in order to minimize the impact of environmental under-stimulation (e.g., boredom) as an antecedent to aggression. Consequently, it is not surprising that findings are absent because these broadband interventions do not address specific causes of aggression for specific individuals.

Furthermore, the activities used in some of these studies are not based on the preferences of individual participants. For example, studies by Hammar et al., ${ }^{[46]}$ Nordgren and Engstrom $^{[31]}$ and Shin ${ }^{[34]}$ provided PWDs access to activities such as singing, dogs, or dolls without assessing if participants preferred these activities. The result is that the benefits of the intervention likely varied greatly across participants, thereby drowning out any effects the intervention might have had on the entire sample. Recommended improvements to studies in this area of inquiry include attempting to match interventions to specific subsets of PWDs based on preferences or the function of aggression (e.g., is aggression related to an excess or deficiency of environmental stimulation). Baker et al., ${ }^{[55]}$ Chou et al., ${ }^{[43]}$ and Fisher and Buchanan ${ }^{[48]}$ represent good examples of studies that have incorporated individualized assessment and intervention strategies.

\section{Conclusions}

Aggressive behaviors in PWDs occur frequently and can have negative consequences for PWDs and their care providers. The medications used to manage aggression have numerous negative side effects, including an increased risk of falling, excessive sedation, and disorientation. Non-pharmacological interventions represent an attractive alternative to medications. ${ }^{[29]}$ This previous review also concluded, however, that the body of literature on non-pharmacological interventions was relatively small and many methodological limitations existed. The purpose of this paper was to provide an updated review of the literature in this area over the last decade to determine where progress has been made and where future research should be directed.

This paper included a review of an additional 12 empirical studies conducted since 2007. Therefore, the literature on non-pharmacological interventions remains small. Additional studies support previous conclusions that comprehensive staff education programs that teach multiple communication and behavior management skills generally produce positive results. Recent research also indicates that distraction-based interventions are promising, particularly for targeting aggression that occurs during hands-on ADLs. Bright light therapy and a variety of different activity-based interventions have generally produced disappointing results.

Several methodological limitations still exist in this literature, particularly regarding small sample sizes, the limited manner in which aggression is measured, a lack of individualization of assessment and intervention approaches, and a failure to assess the impact of interventions on care providers. Based on this updated review, it is encouraging that there is continued research interest in this important topic and we are optimistic that continued research will address the limitations outlined here. The authors hope this line of inquiry will result in the development of evidence-based guidelines and decision models that allow care providers to rapidly design optimal interventions for the PWDs for whom they provide care.

\section{CONFlicts OF INTEREST Disclosure}

The authors declare they have no conflicts of interest. 


\section{REFERENCES}

[1] Potts HW, Richie MF, Kass MJ. Resistance to care. Journal of Gerontological Nursing. 1996; 22(11): 11-16. https://doi.org/10.3 928/0098-9134-19961101-06

[2] Cohen-Mansfield J, Billig N. Agitated behaviors in the elderly: A conceptual review. Journal of the American Geriatric Society. 1986; 34: 711-721. https://doi.org/10.1111/j.1532-5415.1986 .tb04302.x

[3] Jackson JL, Mallory R. Aggression and Violence Among Elderly Patients, a Growing Health Problem. Journal of General Internal Medicine. 2009; 24(10): 1167-1168. https://doi.org/10.100 7/s11606-009-1099-1

[4] Holtzer R, Tang MX, Devanand DP, et al. Psychopathological features in Alzheimer's disease: Course and relationship with cognitive status. JAGS. 2013; 51: 953-960. https ://doi .org/10.1046/j . 1365-2389.2003.51308. $x$

[5] Kunik ME, Snow AL, Davila JA, et al. Consequences of aggressive behavior in patients with dementia. The Journal of Neuropsychiatry and Clinical Neurosciences. 2010; 22: 40-47. https ://doi .org/ 10.1176/jnp.2010.22.1.40

[6] Brazil K, Maitland J, Walker M, et al. The characteristics of behavioural symptoms on admission to three Canadian long-term care homes. Aging and Mental Health. 2013; 17(8): 1059-1066. https://doi.org/10.1080/13607863.2013.807423

[7] Kverno KS, Rabins PV, Blass DM, et al. Prevalence and treatment of neuropsychiatric symptoms in advanced dementia. Journal of Gerontological Nursing. 2008; 34(12): 8-15. https ://doi .org/10.392 8/00989134-20081201-03

[8] Keene J, Hope T, Fairburn CG, et al. Natural history of aggressive behaviour in dementia. International Journal of Geriatric Psychiatry. 1999; 14(7): 541-548. https://doi.org/10.1002/(SICI) 109 9-1166 (199907) $14: 7<541$ : :AID-GPS961>3.0.CO;2-P

[9] Galindo-Garre F, Volcier L, van der Steen JT. Factors related to rejection of care and behaviors directed toward others: A longitudinal study in nursing home residents with dementia. Dementia and Geriatric Disorders Extra. 2015; 5(1): 123-134. PMid: 25999979. https://doi.org/10.1159/000369158

[10] Majić T, Pluta JP, Mell T, et al. Correlates of agitation and depression in nursing home residents with dementia. International Psychogeriatrics. 2012; 24(11): 1779-1789. https ://doi.org/10.1017/S1 04161021200066X

[11] Orengo CA, Khan J, Kunik ME, et al. Aggression in individuals with newly diagnosed dementia. American Journal of Alzheimer's Disease and Other Dementias. 2008; 23(3): 227-232. https://doi.org/ $10.1177 / 1533317507313373$

[12] Gilley DW, Bienias JL, Wilson RS, et al. Influence of behavioral symptoms on rates of institutionalization for persons with Alzheimer's disease. Psychological Medicine. 2004; 34(6): 11291135. https://doi.org/10.1017/S0033291703001831

[13] Yamamoto Y, Hayashino Y, Yamazaki S, et al. Violent patient behavior is associated with bodily pain and a high burden on informal caregivers. Journal of General Internal Medicine. 2009; 24(10): 10851088. https://doi.org/10.1007/s11606-009-1060-3

[14] Hagen BF, Sayers D. When caring leaves bruises: The effects of staff education on resident aggression. Journal of Gerontological Nursing. 1995; 21: 7-16. https : //doi .org/10.3928/0098-9134-19951 101-04

[15] Squillace MR, Remsburg RE, Harris-Kojetin LD, et al. The national nursing assistant survey: Improving the evidence base for policy initiatives to strengthen the certified nursing assistant workforce. The Gerontologist. 2009; 49(2): 185-197. https ://doi.org/10.109 $3 /$ geront/gnp024
[16] Seitz DP, Gill SS, Herrmann N, et al. Pharmacological treatments for neuropsychiatric symptoms of dementia in long-term care: A systematic review. International Psychogeriatrics. 2013; 25(2): 185-203. https://doi.org/10.1017/S1041610212001627

[17] Corbett A, Burns A, Ballard C. Don't use antipsychotics routinely to treat agitation and aggression in people with dementia. BMJ. 2014; 349: 1-4. PMid: 25368388. https ://doi.org/10.1136/bmj.g6 420

[18] Ballard C, Hanney ML, Theodoulou M, et al. The dementia antipsychotic withdrawal trial (DART-AD): Long-term follow-up of a randomised placebo-controlled trial. Lancet Neurology. 2009; 8(2): 151157. https : //doi .org/10.1016/S1474-4422(08)70295-3

[19] Epstein NU, Guo R, Farlow MR, et al. Medication for Alzheimer's disease and associated fall hazard: A retrospective cohort study from the Alzheimer's disease neuroimaging initiative. Drugs \& Aging 2013; 31(2): 125-129. https://doi.org/10.1007/s40266-013 $-0143-3$

[20] Kales HC, Kim HM, Zivin K, et al. Risk of Mortality Among Individual Antipsychotics in Patients With Dementia. American Journal of Psychiatry. 2012; 169(1): 71-79. https ://doi.org/10.1176/ appi.ajp. 2011.11030347

[21] Schneider LS, Dagerman KS, Insel P. Risk of death with atypical antipsychotic drug treatment for dementia: Meta-analysis of randomized placebo-controlled trials. JAMA. 2005; 294(15): 1934-1943. https://doi.org/10.1001/jama.294.15.1934

[22] Yury C, Fisher JE. Meta-analysis of the effectiveness of atypical antipsychotics for the treatment of behavioral problems in persons with dementia. Psychotherapy and Psychosomatics. 2007; 76: 213-218. https ://doi.org/10.1159/000101499

[23] Fisher JE, Swingen DN. Contextual factors in the assessment and management of aggression in dementia patients. Cognitive and $\mathrm{Be}$ havioral Practice. 1997; 4: 171-190. https ://doi.org/10.1016/ S1077-7229 (97) 80017-X

[24] Gates D, Fitzwater E, Meyer U. Violence against caregivers in nursing homes: Expected, tolerated, and accepted. Journal of Gerontological Nursing. 1999; 25: 12-22. https ://doi.org/10.3928/0098-9 134-19990401-05

[25] Talerico KA, Evans LK. Making sense of aggressive/protective behaviors in persons with dementia. Alzheimer's Care Quarterly. 2000; 1(4): 77-88.

[26] Fisher JE, Drossel C, Yury C, et al. A contextual model of restraint free care for persons with dementia. In P. Sturmey (Ed.), The handbook of functional analysis in clinical treatment. New York: Elsevier; 2007. 211-237 p. https://doi.org/10.1016/B978-012372544 $-8 / 50013-6$

[27] Centers for Medicare and Medicaid Services. CMS announces partnership to improve dementia care in nursing homes. 2012 Available from: https://www.cms.gov/Newsroom/MediaRele aseDatabase/Press-Releases/2012-Press-Releases-Ite $\mathrm{ms} / 2012-05-30 . \mathrm{html}$

[28] Centers for Medicare and Medicaid Services. National partnership to improve dementia in nursing homes. 2017. Available from: https : //www.cms.gov/Medicare/Provider-Enrollment-a nd-Certification/SurveyCertificationGenInfo/Nation al-Partnership-to-Improve-Dementia-Care-in-Nursing -Homes.html

[29] Buchanan JA, Christenson AM, Ostrom C, et al. Nonpharmacological interventions for aggression in persons with dementia: A review of the literature. The Behavior Analyst Today. 2007; 8(4): 413-425. https ://doi.org/10.1037/h0100630

[30] Cohen-Mansfield J. Conceptualization of agitation: Results based on the Cohen-Mansfield agitation inventory and the agitation behavior 
mapping instrument. International Psychogeriatrics. 1996; 8(Suppl 3): 309-315.

[31] Nordgren L, Engström G. Effects of dog-assisted intervention on behavioural and psychological symptoms of dementia. Nursing Older People. 2014; 26(3): 31-38. https://doi.org/10.7748/nop201 4.03.26.3.31.e517

[32] Cohen-Mansfield J, Marx MS, Rosenthal AS. A description of agitation in a nursing home. Journal of Gerontology: Medical Sciences. 1989; 44(3): 77-84. https://doi.org/10.1093/geronj/44.3. M77

[33] Chang F, Huang H, Lin K, et al. The effect of a music programme during lunchtime on the problem behaviour of the older residents with dementia at an institution in Taiwan. Journal of Clinical Nursing. 2010; 19(7-8): 939-948. https ://doi.org/10.1111/j.1365-2 $702.2009 .02801 . \mathrm{x}$

[34] Shin JH. Doll Therapy: An intervention for nursing home residents with dementia. Journal of Psychosocial Nursing and Mental Health Services. 2015; 53(1): 13-18. https://doi.org/10.3928/0279 3695-20141218-03

[35] Weiner MF, Martin-Cook K, Svetlik DA. The quality of life in latestage dementia (QUALID) scale. Journal of the American Medical Directors Association. 2000; 1: 114-116. PMid: 12818023.

[36] Fu C, Moyle W, Cooke M. A randomised controlled trial of the use of aromatherapy and hand massage to reduce disruptive behaviour in people with dementia. BMC Complementary and Alternative Medicine. 2013; 13(1). https://doi.org/10.1186/1472-688 2-13-165

[37] Chrzescijanski D, Moyle W, Creedy D. Reducing dementia-related aggression through a staff education intervention. Dementia. 2007; 6(2): 271-286. https://doi.org/10.1177/14713012070803 69

[38] Prodger N, Hurley J, Clarke C. Queen Elizabeth Behavioural Assessment Graphical System. The Australian Journal of Advanced Nursing. 1992; 9: 4-11. PMid: 1295511.

[39] Deudon A, Maubourguet N, Gervais X, et al. Non-pharmacological management of behavioural symptoms in nursing homes. International Journal of Geriatric Psychiatry. 2009; 24(12): 1386-1395 https://doi.org/10.1002/gps.2275

[40] Gozalo P, Prakash S, Qato DM, et al. Effect of the Bathing Without a Battle Training Intervention on Bathing-Associated Physical and Verbal Outcomes in Nursing Home Residents with Dementia: A Randomized Crossover Diffusion Study. Journal of the American Geriatrics Society. 2014; 62(5): 797-804. https ://doi .org/10.1 $111 /$ jgs. 12777

[41] Karlin BE, Visnic S, McGee JS, et al. Results from the multisite implementation of STAR-VA: a multicomponent psychosocial intervention for managing challenging dementia-related behaviors of veterans. Psychological Services. 2014; 11(2): 200-208. https: //doi.org/10.1037/a0033683

[42] Visser SM, Mccabe MP, Hudgson C, et al. Managing behavioural symptoms of dementia: Effectiveness of staff education and peer support. Aging \& Mental Health. 2008; 12(1): 47-55. https: //doi.org/10.1080/13607860701366012
[43] Chou W, Waszynski C, Kessler J, et al. Using positive images to manage resistance-to-care and combative behaviors in nursing home residents with dementia: A pilot study. Geriatric Nursing. 2016; 37(3): 215-220. https://doi.org/10.1016/j.gerinurse .20 16.02 .013

[44] Lang PJ, Bradley MM, Cuthbert BN. International affective picture system (IAPS): Affective ratings of pictures and instruction manual. Technical Report A-8. Gainesville, FL: University of Florida; 2008.

[45] Bogner J. The Agitated Behavior Scale. The Center for Outcome Measurement in Brain Injury. 2000. Available from: http://www. tbims.org/combi/abs

[46] Hammar LM, Emami A, Götell E, et al. The impact of caregivers' singing on expressions of emotion and resistance during morning care situations in persons with dementia: an intervention in dementia care. Journal of Clinical Nursing. 2011; 20(7-8): 969-978. https://doi.org/10.1111/j.1365-2702.2010.03386.x

[47] Mahoney EK, Hurley AC, Volicer L, et al. Development and testing of the resistiveness to care scale. Research in Nursing \& Health. 1999; 22(1): 27-28. https://doi.org/10.1002/(SICI) 1098-2 40X (199902) $22: 1<27::$ AID-NUR4>3 . 0. CO 2 - T

[48] Fisher JE, Buchanan JA. Presentation of preferred stimuli as an intervention for aggression in a person with dementia. Behavior Analysis: Research and Practice. In press.

[49] Hoeffer B, Rader J, McKenzie D, et al. Reducing aggressive behavior during bathing cognitively impaired nursing home residents. Journal of Gerontological Nursing. 1997; 23: 16-23. https://doi.org/ 10.3928/0098-9134-19970501-07

[50] Savage T, Crawford I, Nashed Y. Decreasing assault occurrence on a psychogeriatric ward. Journal of Gerontological Nursing. 2004; 30: 30-37. https://doi .org/10.3928/0098-9134-20040501-08

[51] Sloane PD, Hoeffer B, Mitchell MC, et al. Effect of person-centered showering and the towel bath on bathing-associated aggression, agitation, and discomfort in nursing home residents: A randomized, controlled trial. Journal of the American Geriatrics Society. 2004; 52: 1795-1804. https://doi.org/10.1111/j.1532-5415.2004.5 2501. $\mathrm{x}$

[52] Wolf MM. Social validity: The case for subjective measurement. Journal of Applied Behavior Analysis. 1978; 11: 203-214. https: //doi.org/10.1901/jaba.1978.11-203

[53] Roth AJ, Kornblith AB, Batel-Copel L, et al. Rapid screening for psychologic distress in men with prostate carcinoma: a pilot study. Cancer. 1998; 82: 1904-1908. https: //doi.org/10.1002/(SICI) 1097-0142(19980515)82: 10<1904: : AID-CNCR13>3. 0.CD; $2-X$

[54] Maslach C, Jackson SE, Leiter MP. Maslach burnout inventory manual, (3rd edition). Palo Alto, CA: Consulting Psychologists Press; 1996.

[55] Baker JC, Hanley GP, Mathews RM. Self-administered functional analysis and treatment of aggression by an elder with dementia. Journal of Applied Behavior Analysis. 2006; 39: 469-474. https : //doi.org/10.1901/jaba.2006.80-05 